\title{
Predictors of hypoxemia after general anesthesia in the early postoperative period in a hospital in Ethiopia: an observational study
}

\author{
Moges Gelaw Taye, ${ }_{1}^{1}$ Amelework Molla, ${ }^{1}$ Diriba Teshome, ${ }^{1}$ Metages Hunie, ${ }^{1}$ Simegnew Kibret, ${ }^{1}$ Yewlsew Fentie, ${ }^{1}$ \\ Netsanet Temesgen, ${ }^{1}$ Melaku Tadege Engidaw, ${ }^{2}$ Efrem Fenta ${ }^{1}$ \\ ${ }^{1}$ Department of Anesthesia; ${ }^{2}$ Department of Public Health, College of Health Sciences, Debre Tabor University, Debre Tabor, \\ Ethiopia
}

Background: Early postoperative hypoxemia is a common problem after general anesthesia. The identification of factors associated with an increased occurrence of it might help healthcare professionals to hypoxemia risk patients, therefore this study aims to assess the incidence and factors associated with early postoperative hypoxemia among surgical procedures.

Methods: A prospective cohort study design was conducted from February 1, 2020 to June 30, 2020, on a total of 424 patients who underwent surgery under general anesthesia in Debre Tabor Comprehensive Specialized Hospital. The data was collected using a structured checklist. Bivariable and multivariable logistic regressions were used to check the association.

Results: The incidence of early postoperative hypoxemia was $45.8 \%$. Patients having a BMI of $25-29.9 \mathrm{~kg} / \mathrm{m}^{2}$ and $\mathrm{BMI}$ of $30-39.9 \mathrm{~kg} / \mathrm{m}^{2}$, patients having a chronic disease, current smokers, $\mathrm{SPO}_{2}$ reading before induction of less than $95 \%$, emergency surgery, and the absence of oxygen therapy during the period of transfer and/or in the post anesthesia care unit were significantly associated with an increased risk of hypoxemia in the early postoperative period Conclusions: The incidence of early postoperative hypoxemia was high in Debre Tabor Comprehensive Specialized Hospital. Obese patients, patients having a chronic disease, current smokers, and lower oxygen saturations before induction, emergency surgery, and the absence of oxygen therapy were the main predictors of an increased occurrence of early postoperative hypoxemia.

Key words: Postoperative hypoxemia; general anesthesia; Ethiopia.

Correspondence: Moges Gelaw Taye, Department of Anesthesia, College of Health Sciences, Debre Tabor University, Tewodros II Street, Debre Tabor, Ethiopia. E-mail: mgsglwty@gmail.com

Conflict of interest: The authors declare that they have no competing interests, and all authors confirm accuracy.

Contributions: All authors have made equal contributions to the conception and design of the study, and acquisition of data, and analysis and interpretation of data, drafting the article or revising it critically for important intellectual content. All authors read and verify the manuscript for publication. All the authors have read and approved the final version of the manuscript and agreed to be accountable for all aspects of the work.

Ethics approval and informed consent: Ethical clearance was obtained from the Debre Tabor University Ethical Review Committee. Informed written consent was secured from every study participant before the start of the data collection. Confidentiality and anonymity were ensured.

Availability of data and materials: The datasets used and/or analyzed during the current study are available from the corresponding author on reasonable request. 


\section{Introduction}

The early postoperative period is considered to be the critical period for the development of hypoxemia [1,2]. This occurrence is common in the post-anesthesia care unit after major abdominal, orthopedic, gynecologic, and obstetrics procedures [1]. It is not restricted to the seriously ill patients but may occur in otherwise healthy ones $[3,4]$. Postoperative hypoxemia occurred secondary to impaired gas exchange during anesthesia as a result of reduced tone in the muscles of the chest wall persisting into the postoperative period $[5,6]$. Pulse oximetry is commonly used monitoring to diagnose hypoxemia. Normal pulse oximeter readings should always be 95 to $100 \%$ during anesthesia and recovery from anesthesia. If the oxygen saturation is $94 \%$ or lower, the patient is hypoxemic and needs to be treated quickly. A saturation of less than $90 \%$ is a clinical emergency in postoperative patients. Diagnosis of hypoxemia with the help of a pulse oximeter would lead to early correction of the hypoxemic event [7].

Despite recent advances in anesthesia and surgical care, the incidence of hypoxemia has remained high because of the increasing complexity of the surgery and condition of patients $[8,9]$. The incidence of hypoxemia is highest during the early postoperative period which results in worse outcomes such as myocardial ischemia, organ dysfunction, mental confusion, delirium, wound infection, prolonged hospital stay, and increased cost for the hospital and patient [10-14].

Factors that may involve hypoventilation, diffusion hypoxia, V/Q imbalance, atelectasis, and increased oxygen demand are respiratory depressants (opioids, anesthetic drugs), shock, prolonged surgery, pre-existing cardiovascular diseases, respiratory disease, positioning, acute trauma, ASA level, age, and obesity [15-18]. This study aims to assess the incidence and factors associated with early postoperative hypoxemia among surgical procedures.

\section{Methods}

\section{Study design, area, period and population}

This prospective observational study was conducted in Debre Tabor Comprehensive Specialized hospital from February 01, 2020 to June 30, 2020. Debre Tabor Comprehensive Specialized Hospital is a public Hospital established in 1934 and located in South Gondar Zone, Amara region $667 \mathrm{~km}$ NorthWest of Addis Ababa, the capital city of Ethiopia. The climate of this town is warm-moderate and has a latitude and longitude of $11051^{\prime} \mathrm{N} 3801$ 'E/11.8500N 38.0170E with an elevation of 2,706 meters above sea level [19]. The Hospital has three surgical operation rooms, two orthopedic operation rooms, and two gynecologic and obstetrics operation rooms. The study population of our study consists of patients who underwent surgery under general anesthesia and met the inclusion criteria.

\section{Inclusive criteria}

Patients older than 18 years undergoing surgery under general anesthesia, and patients who were extubated on the operation table were included.

\section{Exclusive criteria}

Preoperative hypoxemia; patients entering the surgical unit having had oxygen therapy; intraoperative use of methylene blue; problems in taking an $\mathrm{SPO}_{2}$ reading; patients who were transferred to intensive care unit (ICU) were excluded.

\section{Sample size determination and sampling technique}

The sample size was calculated by taking the following assumption; the proportion of early postoperative hypoxemia is $50 \%$, confidence interval of $95 \%$, and margin of error of 0.05 . The sample size was determined using the following single population proportion formula:

$\mathrm{n}=\left(\mathrm{Z}_{\alpha / 2}\right)^{2} \mathrm{P}(1-\mathrm{P}) / \mathrm{d}^{2}$

whereas: $\mathrm{n}=$ sample size; $\mathrm{z}=$ confidence interval (1.96); $\mathrm{p}=$ estimated prevalence $(0.5)$; $\mathrm{d}=$ margin of sampling error to be tolerated (0.05). By adding $10 \%$ of sample size (non-respondent rate) final sample size was $385+39=424$. A non-probable convenient sampling technique was used.

\section{Data collection}

Data were collected using a structured questionnaire and the collection of information commenced from the start of the transfer of the patient from the operation theatre and continued to the first $20 \mathrm{~min}$ in the post anesthesia care unit (PACU). As patient returned to the recovery room, the arterial oxygen, saturation level was measured immediately with pulse oximetry then every 5 min till 20 min. A questionnaire was developed from different bibliographic research $[2,20,21]$, which includes demographic and patient-related data, surgery-related data, and anesthetic-related data. Demographic and patient-related characteristics: age, sex, ASA, BMI, smoking status, history of the medical disease; surgery-related characteristics: Type of surgery, the urgency of the procedure, positioning, the estimated blood loss, necessity of blood transfusion; anesthetic-related characteristics: premedication, $\mathrm{SPO}_{2}$ reading before induction, IV induction agent, muscle relaxant, use of reversal (neostigmine), analgesics used, the total amount of intraoperative fluid, time from intubation to extubation, oxygen therapy during patient transfer and/or PACU, and sedation score.

\section{Data quality assurance}

After training, the questionnaire was given to data collectors, and data was properly collected and filled in the prepared format. The principal investigator will supervise the data collectors and check for the completeness of the data daily. To ensure the quality of data, a pre-test of the questionnaire was done on surgical patients at Felege Hiwot Referral hospital.

\section{Data analysis}

After completion of data collection, the data were manually checked for errors; coded, and entered into STATA ${ }^{\mathrm{TM}}$ v. 16 for analysis. Descriptive statistics were used to summarize data. Bivariate and multivariate analyses were used to check the association between the independent variables with the dependent variable (early postoperative hypoxemia). Independent variables were analyzed by using binary logistic regression with the dependent variable and those with a $\mathrm{p}$ of $\leq 0.2$ were fitted to a multivariate analysis. In multivariate analysis, a p of less than or equals to 0.05 was used as a cut of point for the presence of association. Tables were used to display the results of this study.

\section{Operational definition}

Early postoperative hypoxemia: the appearance of hypoxemia $\left(\mathrm{SpO}_{2}<90 \%\right)$ during the transfer of the patient from operation theatre and within $20 \mathrm{~min}$ postoperatively in the PACU [1]. Hypoxemia was categorized as mild $\left(90 \%>\mathrm{SpO}_{2} \geq 86 \%\right)$, moderate $\left(86 \%>\mathrm{SpO}_{2} \geq 81 \%\right)$, and severe $\left(\mathrm{SpO}_{2}<81 \%\right)$ [1]. 


\section{Results}

A total of 424 patients were included in this study with a response rate of $100 \%$. The majority $(72.9 \%)$ of the study participants were between the ages of 18 to 65 , and most of the study participants were ASA physical status I (46\%) (Table 1).

\section{Surgery-related characteristics of the study partici- pants}

Among the various types of surgeries, the highest proportion of early postoperative hypoxemia occurred in patients who underwent abdominal surgery $(20.3 \%)$. Early postoperative hypoxemia was found to be more common in emergency surgeries compared with elective surgeries $(23.1 \%$ vs $22.6 \%$ - 98/166 vs 96/258) (Table 2).

Table 1. Demographic and patient-related characteristics of the study participants at Debre Tabor Comprehensive Specialized Hospital 2020/2021 $(n=424)$.

\begin{tabular}{|c|c|c|c|}
\hline \multirow[t]{2}{*}{ Variables } & \multicolumn{2}{|c|}{ Hypoxemia } & \multirow[t]{2}{*}{ Total, n (\%) } \\
\hline & Yes, n (\%) & No, n (\%) & \\
\hline \multicolumn{4}{|l|}{ Age (years) } \\
\hline $18-65$ & $139(32.8)$ & $170(40.1)$ & $309(72.9)$ \\
\hline$>65$ & $55(12.9)$ & $60(14.2)$ & $115(27.1)$ \\
\hline \multicolumn{4}{|l|}{ Sex } \\
\hline Female & $92(21.7)$ & $107(25.2)$ & $199(46.9)$ \\
\hline Male & $102(24.1)$ & $123(29.0)$ & $225(53.1)$ \\
\hline \multicolumn{4}{|l|}{ BMI $\left(\mathrm{kg} / \mathrm{m}^{2}\right)$} \\
\hline $18.5-24.9$ & $105(24.8)$ & $157(37.0)$ & $262(61.8)$ \\
\hline $25-29.9$ & $26(6.1)$ & $17(4.0)$ & $43(10.1)$ \\
\hline $30-39.9$ & $41(9.7)$ & $24(5.7)$ & $65(15.3)$ \\
\hline$<18$ & $22(5.2)$ & $32(7.5)$ & $54(12.7)$ \\
\hline \multicolumn{4}{|l|}{ ASA physical status } \\
\hline ASA I & $91(21.5)$ & $104(24.5)$ & $195(46.0)$ \\
\hline ASA II & $73(17.2)$ & $102(24.1)$ & $175(41.3)$ \\
\hline ASA III & $30(7.1)$ & $24(5.7)$ & $54(12.7)$ \\
\hline \multicolumn{4}{|l|}{ Smoking } \\
\hline Yes & $30(7.1)$ & $18(4.2)$ & $48(11.3)$ \\
\hline No & $164(38.7)$ & $212(50.0)$ & $376(88.7)$ \\
\hline \multicolumn{4}{|l|}{ Presence of coexisting disease } \\
\hline Had no chronic disease & $108(25.5)$ & $186(43.9)$ & $294(69.4)$ \\
\hline Hypertension & $42(9.9)$ & $30(7.1)$ & $72(17.0)$ \\
\hline Bronchial asthma & $44(10.4)$ & $14(3.3)$ & $58(13.7)$ \\
\hline
\end{tabular}

Table 2. Surgery-related characteristics of the study participants at Debre Tabor Comprehensive Specialized Hospital 2020/2021 $(n=424)$.

\begin{tabular}{|c|c|c|c|}
\hline Variables & & & Total, n (\%) \\
\hline & Yes, n (\%) & No, n (\%) & \\
\hline Urgency of the procedure & & & \\
\hline Elective & $96(22.6)$ & $162(38.2)$ & $258(60.8)$ \\
\hline Emergency & $98(23.1)$ & $68(16.0)$ & $166(39.2)$ \\
\hline Type of surgery & & & \\
\hline Abdominal & 86 (20.3) & 116 (27.4) & $202(47.6)$ \\
\hline Thyroidectomy & $36(8.5)$ & $48(11.3)$ & $84(19.8)$ \\
\hline Orthopedic & $24(5.7)$ & $18(4.2)$ & $42(9.9)$ \\
\hline Gynecologic and Obstetric & 48 (11.3) & 48 (11.3) & $96(22.6)$ \\
\hline Positioning & & & \\
\hline Supine & $147(34.7)$ & $185(43.6)$ & $332(78.3)$ \\
\hline Lithotomy & $47(11.1)$ & $45(10.6)$ & $92(21.7)$ \\
\hline Estimated blood loss (ml) & & & \\
\hline$<500$ & $79(18.6)$ & $120(28.3)$ & $199(46.9)$ \\
\hline $500-1000$ & $66(15.6)$ & $75(17.7)$ & $141(33.3)$ \\
\hline $1000-1500$ & $30(7.1)$ & $35(8.3)$ & $65(15.3)$ \\
\hline $1500-2000$ & $16(3.8)$ & $3(0.7)$ & $19(4.5)$ \\
\hline Necessity of transfusion & & & \\
\hline Yes & $17(4.0)$ & $15(3.5)$ & $32(7.5)$ \\
\hline No & $177(41.7)$ & $215(50.7)$ & $392(92.5)$ \\
\hline
\end{tabular}




\section{Anesthetic-related characteristics of the study partici- pants}

Among the various types of surgeries, the highest proportion of early postoperative hypoxemia occurred in patients who underwent abdominal surgery $(20.3 \%)$. Early postoperative hypoxemia was found to be more common in patients who had no oxygen supplementation compared with patients on oxygen therapy during patient transfer and/or in the PACU (23.1\% vs $22.6 \%$
- 98/166 vs 96/258). Early postoperative hypoxemia was common in patients who had lower oxygen saturation before induction $\left(\mathrm{SPO}_{2}<95 \%\right)$ as compared to patients who had higher oxygen saturations before induction $\left(\mathrm{SPO}_{2} \geq 95 \%\right)(4.3 \%$ vs $41.5 \%-18 / 56 v s$ 176/368) (Table 3).

Prevalence and factors associated with early postoperative hypoxemia of the study participants

Early postoperative hypoxemia was found to be in 149 patients

Table 3. Anesthetic-related characteristics of the study participants at Debre Tabor Comprehensive Specialized Hospital 2020/2021 $(n=424)$.

\begin{tabular}{|c|c|c|c|}
\hline Variables & Yes, n (\%) & No, n (\%) & Total, n (\%) \\
\hline $\begin{array}{l}\text { Premedication } \\
\text { Neither } \\
\text { Opioids } \\
\text { Benzodiazepines }\end{array}$ & $\begin{array}{l}103(24.3) \\
79(18.6) \\
12(2.8)\end{array}$ & $\begin{array}{l}122(28.8) \\
85(20.0) \\
23(5.4)\end{array}$ & $\begin{array}{c}225(53.1) \\
164(38.7) \\
35(8.3)\end{array}$ \\
\hline $\begin{array}{l}\mathrm{SPO}_{2}(\%) \text { reading before induction } \\
\quad \geq 95 \\
\quad<95\end{array}$ & $\begin{array}{c}176(41.5) \\
18(4.3)\end{array}$ & $\begin{array}{c}192(45.3) \\
38(8.9)\end{array}$ & $\begin{array}{c}368(86.8) \\
56(13.2)\end{array}$ \\
\hline $\begin{array}{l}\text { Intravenous induction agent } \\
\text { Ketamine } \\
\text { Propofol } \\
\text { Ketofol } \\
\text { Thiopental }\end{array}$ & $\begin{array}{l}24(5.7) \\
51(12.0) \\
66(15.6) \\
53(12.5)\end{array}$ & $\begin{array}{l}30(7.1) \\
56(13.2) \\
59(13.9) \\
85(20.0)\end{array}$ & $\begin{array}{l}54(12.7) \\
107(25.2) \\
125(29.5) \\
138(32.5)\end{array}$ \\
\hline $\begin{array}{l}\text { Muscle relaxant used } \\
\text { Suxamethonium } \\
\text { Vecuronium } \\
\text { Suxamethonium and vecuronium } \\
\text { Not used }\end{array}$ & $\begin{array}{c}6(1.4) \\
11(2.6) \\
146(34.4) \\
31(7.3)\end{array}$ & $\begin{array}{c}10(2.4) \\
18(4.2) \\
177(41.7) \\
25(5.9)\end{array}$ & $\begin{array}{c}16(3.8) \\
29(6.8) \\
323(76.2) \\
56(13.2)\end{array}$ \\
\hline $\begin{array}{l}\text { Number of intubation attempts } \\
\text { Single } \\
\text { Multiple }\end{array}$ & $\begin{array}{c}128(30.2) \\
66(15.6)\end{array}$ & $\begin{array}{c}182(42.9) \\
48(11.3)\end{array}$ & $\begin{array}{l}310(73.1) \\
114(26.9)\end{array}$ \\
\hline $\begin{array}{l}\text { Neostigmine used } \\
\text { Yes } \\
\text { No }\end{array}$ & $\begin{array}{c}157(37.0) \\
37(8.7)\end{array}$ & $\begin{array}{c}188(44.3) \\
42(9.9)\end{array}$ & $\begin{array}{l}345(81.4) \\
79(18.6)\end{array}$ \\
\hline $\begin{array}{l}\text { Intraoperative analgesic used } \\
\text { Diclofenac } \\
\text { Pethidine } \\
\text { Diclofenac and pethidine }\end{array}$ & $\begin{array}{c}13(3.1) \\
107(25.2) \\
749(17.5)\end{array}$ & $\begin{array}{c}18(4.2) \\
113(26.7) \\
99(23.3)\end{array}$ & $\begin{array}{c}31(7.3) \\
220(51.9) \\
177(41.7)\end{array}$ \\
\hline $\begin{array}{l}\text { Intraoperative fluid used (ml) } \\
\quad<1000 \\
1000-2000 \\
2000-3000 \\
>3000\end{array}$ & $\begin{array}{l}24(5.7) \\
25(5.9) \\
84(19.8) \\
61(14.4)\end{array}$ & $\begin{array}{c}23(5.4) \\
36(8.5) \\
135(31.8) \\
36(8.5)\end{array}$ & $\begin{array}{l}47(11.1) \\
61(14.4) \\
219(51.7) \\
97(22.9)\end{array}$ \\
\hline $\begin{array}{l}\mathrm{O}_{2} \text { therapy } \\
\text { Yes } \\
\text { No }\end{array}$ & $\begin{array}{c}18(4.2) \\
176(41.5)\end{array}$ & $\begin{array}{c}44(10.4) \\
186(43.9)\end{array}$ & $\begin{array}{c}62(14.6) \\
362(85.4)\end{array}$ \\
\hline $\begin{array}{l}\text { Shiver in PACU } \\
\text { Yes } \\
\text { No }\end{array}$ & $\begin{array}{c}47(11.1) \\
147(34.7)\end{array}$ & $\begin{array}{c}45(10.6) \\
185(43.6)\end{array}$ & $\begin{array}{c}92(21.7) \\
332(78.3)\end{array}$ \\
\hline $\begin{array}{l}\text { Sedation score in PACU } \\
\quad 0 \\
1 \\
2 \\
3\end{array}$ & $\begin{array}{l}145(34.2) \\
29(6.8) \\
10(2.4) \\
10(2.4)\end{array}$ & $\begin{array}{l}172(40.6) \\
39(8.8) \\
11(2.6) \\
8(1.9)\end{array}$ & $\begin{array}{l}317(74.8) \\
68(16.0) \\
21(5.0) \\
18(4.2)\end{array}$ \\
\hline $\begin{array}{l}\text { Time from intubation to extubation (min) } \\
\quad<60 \\
\geq 60\end{array}$ & $\begin{array}{c}30(7.1) \\
164(38.7)\end{array}$ & $\begin{array}{c}42(9.9) \\
188(44.4)\end{array}$ & $\begin{array}{c}72(16.9) \\
352(83.0)\end{array}$ \\
\hline
\end{tabular}

PACU, post anesthesia care unit. 
Table 4. Factors associated with early postoperative hypoxemia of the study participants at Debre Tabor Comprehensive Specialized Hospital 2020/2021 ( $=424)$.

\begin{tabular}{|c|c|c|c|c|c|}
\hline Variables & & & COR $(95 \% \mathrm{CI})$ & AOR $(95 \% \mathrm{CI})$ & $\mathbf{p}$ \\
\hline & Yes & No & & & \\
\hline BMI $\left(\mathrm{kg} / \mathrm{m}^{2}\right)$ & & & & & \\
\hline $18.5-24.9$ & 105 & 157 & 1 & 1 & \\
\hline $25-29.9$ & 26 & 17 & $2.287(1.183,4.422)$ & $2.588(1.269,5.276)$ & 0.009 \\
\hline $30-39.9$ & 41 & 24 & $2.554(1.458,4.477)$ & $2.411(1.278,4.548)$ & 0.007 \\
\hline$<18$ & 22 & 32 & $1.028(0.566,1.866)$ & $1.165(0.589,2.304)$ & 0.662 \\
\hline Smoking & & & & & \\
\hline Yes & 30 & 18 & $2.154(1.160,4.001)$ & $2.192(1.095,4.391)$ & 0.027 \\
\hline No & 164 & 212 & 1 & 1 & \\
\hline Urgency & & & & & \\
\hline Elective & 96 & 162 & 1 & 1 & \\
\hline Emergency & 98 & 68 & $2.432(1.631,3.625)$ & $3.193(2.013,5.064)$ & $<0.0001$ \\
\hline Having chronic disease & & & & & \\
\hline Neither & 108 & 186 & 1 & 1 & \\
\hline Hypertension & 42 & 30 & $2.411(1.426,4.076)$ & $3.334(1.835,6.056)$ & $<0.0001$ \\
\hline Bronchial asthma & 44 & 14 & $5.413(2.836,10.336)$ & $7.519(3.706,15.256)$ & $<0.0001$ \\
\hline $\mathrm{SPO}_{2}(\%)$ reading before induction & & & & & \\
\hline$\geq 95$ & 176 & 192 & 1 & 1 & \\
\hline$<95$ & 18 & 38 & $1.935(1.065,3.515)$ & $3.011(1.535,5.908)$ & 0.001 \\
\hline $\mathrm{O}_{2}$ therapy & & & & & \\
\hline Yes & 18 & 44 & 1 & 1 & \\
\hline No & 176 & 186 & $2.313(1.288,4.155)$ & $2.559(1.310,5.001)$ & 0.006 \\
\hline
\end{tabular}

(45.8\%). In this study, obesity was significantly associated with postoperative hypoxemia. Hypoxemia was mild in $80 \%$ of these cases $(\mathrm{n}=155)$; moderate $\left(86 \mathrm{~N} \mathrm{SpO}_{2} \geq 81 \%\right)$ in $12 \%$ of cases $(n=23)$; and severe in $8 \%$ of cases $(n=16)$. Patients who had a BMI of $25-29.9 \mathrm{~kg} / \mathrm{m}^{2}$ were 2.6 times more likely to develop postoperative hypoxemia than normal patients $(\mathrm{AOR}=2.588,95 \% \mathrm{CI}$ : $1.269,5.276$ ). Current smokers were 2.2 times more likely to develop postoperative hypoxemia compared with non-smokers (AOR = 2.192, 95\% CI: 1.095, 4.391). Emergency surgical procedures $(\mathrm{AOR}=3.193), 95 \% \mathrm{CI}: 2.013,5.064)$, patients who had a history of bronchial asthma (AOR $=7.519,95 \% \mathrm{CI}: 3.706,15.256)$, hypertensive patients $(\mathrm{AOR}=3.334,95 \% \mathrm{CI}: 1.835,6.056)$, patients who had lower oxygen saturation before induction $\left(\mathrm{SPO}_{2}<95 \%\right)$ before induction $(\mathrm{AOR}=3.011,95 \% \mathrm{CI}: 1.535,5.908)$, and the absence of oxygen therapy during the period of transfer of the patient from operation theatre and/or in the PACU $(\mathrm{AOR}=2.559$, $95 \%$ CI: $1.310,5.001)$ were more likely to develop early postoperative hypoxemia than their counterparts (Table 4).

\section{Discussion}

Early postoperative hypoxemia was found to be in 149 patients (45.8\%). In this study, obesity was significantly associated with postoperative hypoxemia. Patients who had a BMI of $25-29.9 \mathrm{~kg} / \mathrm{m}^{2}$ were 2.6 times more likely to develop postoperative hypoxemia than normal patients $(\mathrm{AOR}=2.588,95 \% \mathrm{CI}: 1.269,5.276)$. Despite the recent advances in anesthesia and surgical care, early postoperative hypoxemia is still a common problem after general anesthesia. The identification of factors associated with an increased occurrence of early postoperative hypoxemia could help alert staff to hypoxemia risk patients. In this study, the overall incidence of early postoperative hypoxemia was found to be $45.8 \%$. In line with our result, a study conducted in Canada by Denise et al. showed that $41 \%$ of patients had at least one episode of hypoxemia during their PACU stay following surgery [22]. In contrary to our finding studies showed a lower incidence of early postoperative hypoxemia such as studies conducted in Japan by Ishikawa et al. [23] (12.7\%), a study done in Brazil by Filho et al. [24] (24.1\%), and a study in the USA by Ramachandran et al. 10.7-22\% [22]. This discrepancy might be due to a variation in study settings where the above developed countries could have a better perioperative patient care as compared to the developing ones like Ethiopia. The incidence of hypoxemia in studies done in Ethiopia was 22.7\% [25] and 26.7\% [20] in Tikur Anbesa Comprehensive Specialized hospital and in University of Gondar hospital, respectively. In this study, we identified that patients with a BMI $>25 \mathrm{~kg} / \mathrm{m}^{2}$, having a chronic disease (hypertension and bronchial asthma), current smokers, with lower oxygen saturation before induction $\left(\mathrm{SpO}_{2}<95 \%\right)$, emergency surgery, and the absence of oxygen therapy during the period of transfer of the patient from operation theatre and/or in the PACU were all significantly associated with increased hypoxemia in the early postoperative period. This finding was similar to various studies, which showed that patients who had respiratory co-morbidity $[25,26]$ and were smokers $[20,23,26]$, patients who were obese $[23,26]$, withlower preoperative oxygen saturation $\left(\mathrm{SPO}_{2}<95 \%\right)[7,20,24$,] were significantly associated with increased hypoxemia.

\section{Conclusions}

The findings of this study showed that obese patients, patients having a chronic disease (hypertension and asthma), current smokers, lower oxygen saturation before induction ( $\mathrm{SpO} 2<95 \%$ ), emergency surgery, and the absence of oxygen therapy during patient transfer and/or in the PACU were the main predictors of an increased occurrence of early postoperative hypoxemia. The identification of these factors may help to alert healthcare professionals to hypoxemia risk patients. 


\section{Acknowledgments}

Debre Tabor University and Debre Tabor Comprehensive Specialized Hospital Staffs.

\section{Abbreviations}

AOR: adjusted odds ratio;

ASA: American Society of Anesthesiology;

BMI: body mass index;

CI: confidence interval;

COR: crude odds ratio;

DBP: diastolic blood pressure;

DTCSH: Debre Tabor comprehensive specialized hospital;

PACU: post anesthesia care unit;

SBP: systolic blood pressure.

\section{References}

1. Maity A, Saha D, Swaika S, Maulik SG, Choudhury B, Sutradhar M. Detection of hypoxia in the early postoperative period. Anesth Essays Res 2012;6:34.

2. Siddiqui N, Arzola C, Teresi J, Fox G, Guerina L, Friedman Z. Predictors of desaturation in the postoperative anesthesia care unit: an observational study. J Clin Anesth 2013;25:612-7.

3. Rosenberg J, Pedersen M, Gebuhr P, Kehlet H. Effect of oxygen therapy on late postoperative episodic and constant hypoxaemia. BJA: Br J Anaesth 1992;68:18-22.

4. Dalesio NM, McMichael DH, Benke JR, Owens S, Carson KA, Schwengel DA, et al. Are nocturnal hypoxemia and hypercapnia associated with desaturation immediately after adenotonsillectomy? Pediatr Anaesth 2015;25:778-85.

5. Vaughan RW, Engelhardt RC, Wise L. Postoperative hypoxemia in obese patients. Ann Surg 1974;180:877.

6. Jones J, Sapsford D, Wheatley R. Postoperative hypoxaemia: mechanisms and time course. Anaesthesia 1990;45:566-73.

7. Brown L, Purcell G, Traugott R F. Hypoxaemia during postoperative recovery using continuous pulse oximetry. Surv Anesthesiol 1991;35:288-9.

8. Uakritdathikarn T, Chongsuvivatwong V, Geater AF, Vasinanukorn M, Thinchana S, Klayna S. Perioperative desaturation and risk factors in general anesthesia. J Med Assoc Thai 2008;91:1020-9.

9. Karcz M, Papadakos PJ. Respiratory complications in the postanesthesia care unit: a review of pathophysiological mechanisms. Can J Respir Ther 2013;49:21.

10. Rosenberg J, Pedersen M, Gebuhr P, Kehlet H. Effect of oxygen therapy on late postoperative episodic and constant hypoxemia. Br J Anaesth 1992;68:18-22.

11. Habre W, Peták F. Perioperative use of oxygen: variabilities across age. Br J Anaesth 2014;113:ii26-ii36.

12. Kawanishi $\mathrm{H}$, Inoue $\mathrm{S}$, Kawaguchi $\mathrm{M}$. A retrospective analysis of oxygen desaturation during acoustic respiratory rate monitoring in non-ICU patients following tracheal extubation after general anesthesia. Anesthesiol Res Pract 2017;2017:4203156.

13. Robson MJ, Alston PR, Deary IJ, Andrews PJ, Souter MJ, Yates S. Cognition after coronary artery surgery is not related to postoperative jugular bulb oxyhemoglobin desaturation. Anesth Analg 2000;91:1317-26.

14. Kieran S, Gorman C, Kirby A, Oyemwense N, Lander L, Schwartz M, et al. Risk factors for desaturation after tonsillectomy: analysis of 4092 consecutive pediatric cases. Laryngoscope 2013;123:2554-9.

15. Razlevice I, Rugyte DC, Strumylaite L, Macas A. Assessment of risk factors for cerebral oxygen desaturation during neonatal and infant general anesthesia: an observational, prospective study. BMC Anesthesiol 2016;16:1-8.

16. Meiklejohn B, Smith G, Elling A, Hindocha N. Arterial oxygen desaturation during postoperative transportation: the influence of operation site. Anaesthesia 1987;42:1313-5.

17. Jones J, Jordan C, Scudder C, Rocke D, Barrowcliffe M. Episodic postoperative oxygen desaturation: the value of added oxygen. J R Soc Med 1985;78:1019-22.

18. Vidhani K, Langham B. Obstructive sleep apnoea syndrome: is this an overlooked cause of desaturation in the immediate postoperative period? Br J Anaesth 1997;78:442-3.

19. Tadesse S, Fesaha G, Abebe A, Hailu B, Dejen W. Assessment of productive and reproductive performances of cross breed dairycows in Debre Tabor town. J Biol Agric Healthcare 2014;4:112-4.

20. Melesse DY, Denu ZA, Kassahun HG, Agegnehu AF. The incidence of early post-operative hypoxemia and its contributing factors among patients underwent operation under anesthesia at University of Gondar comprehensive and specialized referral hospital, Gondar, North West Ethiopia, 2018. A prospective observational study. Int J Surg Open 2020;22:38-46.

21. Labaste F, Silva S, Serin-Moulin L, Lefèvre E, Georges B, Conil JM, et al. Predictors of desaturation during patient transport to the postoperative anesthesia care unit: an observational study. J Clin Anesth 2016;35:210-4.

22. Ramachandran SK, Thompson A, Pandit JJ, Devine S, Shanks AM. Retrospective observational evaluation of postoperative oxygen saturation levels and associated postoperative respiratory complications and hospital resource utilization. PloS One 2017;12:e0175408.

23. Ishikawa M, Sakamoto A. Postoperative desaturation and bradypnea after general anesthesia in non-ICU patients: a retrospective evaluation. J Clin Monit Comput 2020;34:81-7.

24. de Oliveira Filho GR, Garcia JHS, Ghellar MR, Nicolodi MA, Boso AL, Dal Mago AJ. [Factores asociados con la ocurrencia de hipoxemia en el período pós-anestésico inmediato].[Article in Portuguese]. Rev Bras Anestesiol 2001;51:185-95.

25. Wolde GD, Awol MA, Obsa MS, Wesene NG, Gemechu AD, Tadesse EN. Magnitude and associated factors of immediate postoperative hypoxemia among elective surgical procedures at Tikur Anbessa Specialized hospital, Addis Ababa, Ethiopia. J Anesth Clin Res 2018;9:5.

26. Kaushal A, Goyal P, Dhiraaj S, Agarwal A, Singh PK. Identification of various perioperative risk factors responsible for development of postoperative hypoxaemia. Turk J Anaesthesiol Reanim 2018;46:416.

Received for publication: 12 May 2021. Accepted for publication: 7 June 2021.

This work is licensed under a Creative Commons Attribution-NonCommercial 4.0 International License (CC BY-NC 4.0).

CCopyright: the Author(s), 2021

Licensee PAGEPress, Italy

Multidisciplinary Respiratory Medicine 2021; 16:782

doi:10.4081/mrm.2021.782 